\title{
Group Counselling as a Strategy for Stimulating Interest for Literacy
}

\author{
Dr (Mrs) Stella Ngozi Nduka-Ozo
}

Department of Educational Foundations Ebonyi State University Abakaliki.

\begin{abstract}
The focus of this paper is on stimulating interest in literacy: which is dwindling in Nigeria for reasons that range from reluctance on the part of students to 'sorting' as encouraged by teachers. This is an educational problem which any counsellor should he concerned about. Group counselling has an advantage of facilitating group dynamics through exploring problems nurtured and solved in the therapeutic environment so created. The multidimensional approach being advocated in order to tackle the problem of illiteracy and poor reading culture has warranted the recommendations made. In conclusion the paper advocates that literacy and reading should be viewed by counsellors as an educational problem that requires urgent attention.
\end{abstract}

Keywords-Group, Counselling, Strategies, Stimulating, Literacy.

\section{INTRODUCTION}

An illiterate person as viewed by UNESCO (1995), is one "who cannot with understanding both read and write a short simple statement on his/her every day life". Conversely, a literate person is, therefore, one who can with understanding both read and write a simple statement on his/her every day life. The problem here is that majority of the Nigerian population fall into the illiterate class. South (1985), carried out a research in which it was found that about $34 \%$ of adults in Nigeria are still stark illiterates, $16 \%$ have secondary school education, while $3 \%$ have tertiary education. Yet going by UNESCO's concept of 'functional literacy' the percentage of the so called literate population is further reduced when put in the x-ray of real functional competence.

The high rate of decrease in our reading culture today and the concomitant high rate of reading failures among school pupils/students have resulted in low level of literacy even at completion of school programmes. All the 'remedial this' and 'remedial that' in higher institutions have only yielded what Unoh (1982) called "reluctant reading and learning syndrome". This he explained as reading what is specifically required to achieve limited objectives like passing specific examination. Folashade (2004) opined that "poor performance of undergraduates in their subject areas is partly due to insufficient mastery of English language reading which is an important language skill".

The dragons that have further helped in discouraging those who would have bothered to make effort in reading and studies include: sorting (of teachers who themselves were the product of 'cutting corner's') expo, $\mathrm{n}$-made easy (where $\mathrm{n}$ stands for any subject under review). The end result is that many scholars have poor study habit. A research carried out by Brown (1991), has shown that the acquisition of systematic study skills is important in the acquisition of knowledge and competence. Other studies have found that scholastically superior student possess better study habits that students of low achievement. Many learners lack skills in reading efficiency, planning and organizing time for study, note - taking, learning and remembering strategies (Kagu, 2000).

\section{Group Counselling}

When students experience problems; they are expected to seek help from a counsellor. UNESCO says "literacy is a human right; while Nduka-Ozo (2004) says illiteracy or poor reading or study habit is an educational problem that needcounselling. Bakare (1975) recommended counselling as one of the most effective methods of helping students to develop good study habits. When group counselling is employed, it is even more facilitating as the group members help to encourage one another. Group counselling is defined as a dynamic, interpersonal process through which individuals within the normal range of adjustment work within a peer group and with a professionally trained counsellor, exploring problems and feelings in an attempt to modify their attitudes so that they are better able to deal with developmental problems. Gazada (1973) maintained that it is a

Dynamic interpersonal process focusing on conscious thought and behaviour and involving the therapy functions of 
permissiveness, orientation to

reality, cartharsis and mutual

trust, caring, understanding, acceptance and support. The therapy functions are created and nurtured in a small group through the sharing of personal concerns with one '\$ peers and the counsellor.

One advantage of group counselling is economy. Essuman (1981) suggested that group counselling fulfils the Africaness in us since the Africans by nature tend towards 'groupness'. The group is seen as a potential entity for learning. It instils confidence and hope because when individuals engage in group activities they meet with others experiencing the same problem with their own.

Denga (1985), therefore, itemized the following rationales for group counselling:-

1. It fosters a healthy personality adjustment since it provides a forum for a group of individuals to selflessly share their experience.

2. It enables members to understand others and hence themselves.

3. Real life is lived in a group, though the individuals have liberty and opportunity to do certain things in isolation.

4. Some themes or topic lend themselves more economically and expediently to group than individual counselling.

5. Given that a group comprises - shy, bold, the silent or withdrawn, the socialized, the pitiful, the initiator etc, the blend of these traits can positively complement those deficient in the desirable traits.

Asogwa (1996) observed that group counselling "is remedial as well as preventive in nature". The group members may be facing situation crisis, temporary conflicts and other self defeating behaviour which they intend to alter. The group provides the empathy and support necessary to create the atmosphere of trust that leads to the exchanging of exploration of these problems.

All these works done have yielded high correlation between efforts and performance through awareness created in group explanation or" problems and the resultant solution of problem are reviewed and discussed.

\section{Recommendations}

The solution of the problem of literacy now requires a multidimensional approach. So in addition to other recommendations made elsewhere, the following are made from a counsellor's perspective:

1. School counsellors and career masters should declare literacy and reading an educational problem that need urgent attention. Students should be invited to group counselling sessions to discuss the future of a nation with such apathy and nonchalant attitude towards our reading culture.

2. The Reading Association of Nigeria (RAN) should open student chapters in schools for proper sensitisation and participation of the young people who are the next generation.

3. Literacy and debating clubs that use to feature in schools in the past should be revamped and encouraged through adults interests.

4. Adult education centres should not be left out in the pursuit of improved reading and literacy interest since nobody is beyond academic redemption.

5. Prizes and awards should be competed for nationally, in literacy and reading. This is to strengthen the efforts being made at the grassroots level.

\section{CONCLUSION}

To avert the impending doom that looms over the horizon of literacy and reading in particular and education generally in Nigeria, all hand must be on deck. The school counsellors should declare illiteracy and poor reading habit an education problem that needs urgent attention. The older generation should be encouraged to read; whether in schools or out of schools. The younger ones should be made to realize the danger ahead of a non-literate and non-reading society.

\section{REFERENCES}

[1] Bakare C.G.M. (1977), Student Problem Inventory (SPI) Ibadan: University Press

[2] Braun, C.W. (1991), The nature of some of the differences of students family the $1^{\text {st }}$ two years of college. Journal of Exp. Education Vol. 1 p. 26.

[3] Essuman, J.K (1981), Guidance and Counselling in Schools (A hand book) Enugu; Ministry of Education.

[4] Folashade, A.F. (2004), Extensive Reading as Strategy for developing interest for life-long literacy. The Ahmadu Bello, University, Zaria Model. Literacy and reading in Nigeria Vol. 10 No. $1 \mathrm{Pg}$. 74-80.

[5] Gazada, G.M. (1971), Group Counselling. A Developmental Approach Boston: Allyn and Bacon. 
[6] Kagu, B (2000), The effect of group counselling on studying habit patterns of adult learners. The counsellor. 18.148-154.

[7] Nduka-Ozo, S.N. (2004) Effect of two counselling techniques on the study habit patterns of adult learners in Ebonyi State. An M.Ed. Dissertion. Ebonyi State University Abakaliki.

[8] South, (1985), Literacy World Magazine, South Pacific. Wide. South

[9] Stercq, C. (1993), Literacy, Socialisation and Employment, Hamburg: UNESCO.

[10] Unoh, S. (1982), Keynote Address: Reading improvement in Nigeria as a multilingual nation: problems and prospects. Literacy and Reading in Nigeria, Vol. 1: 1-32 